\title{
Verification and Quantification of the Hammond-Leffler Postulate
}

\section{Dieter Cremer \& Elfi Kraka}

O postulado de Hammond-Leffler prevê que reações exotérmicas possuem estados de transições (ET) mais similares a estrutura dos reagentes e as reações endotérmicas mais similares aos produtos. Nós mostramos que esta previsão pode ser verificada calculandose a trajetória de reação e a sua curvatura utilizando métodos de química quântica. A trajetória escalar da curvatura adota o ponto máximo da reação onde há a quebra e a formação de ligações durante o processo químico. É sempre possível definir o centro da área desta trajetória. A mudança do ET em relação a este centro muda linearmente com a energia da reação de valores positivos (reações exotérmicas) a valores negativos (reações endotérmicas) descrevendo assim quantitativamente o caráter do ET como sendo similar aos reagentes ou produtos.

Palavras-chave: postulado de Hammond-Leffler, curvatura da trajetória de reação, aproximação para a unificação dos vales no caminho de reação.

The Hammond-Leffler postulate predicts that exothermic reactions possess an early transition state (TS) and endothermic reactions a late one. We show that this prediction can be verified by calculating the reaction path and its curvature by utilizing quantum chemical methods. The scalar path curvature adopts maxima where the chemical processes of bond breaking and forming take place. It is always possible to define the center of this path area. The shift of the TS with regard to this center changes linearly with the reaction energy from positive values (exothermic reactions) to negative values (endothermic reactions) thus quantitatively describing the character of the TS as being early or late.

Keywords: Hammond-Leffler postulate, reaction path curvature, unified reaction valley approach. 


\section{Introduction}

In a seminal article entitled "A Correlation of Reaction Rates" submitted in 1953 and printed in early 1955, Hammond ${ }^{1}$ set up the following postulate: If two states, as for example, a transition state and an unstable intermediate, occur consecutively during a reaction process and have nearly the same energy content, their interconversion will involve only a small reorganization of the molecular structures. Hammond's postulate was based on transition state theory and was applied by him as it is found in today's textbooks of organic chemistry: In a highly exothermic reaction, the transition state (TS) should closely resemble the reactants, in a highly endothermic reaction the products, whereas for a thermoneutral reaction the TS has no close analog of conventional chemical structure. ${ }^{1}$ This can be reformulated in the following way: Exothermic reactions possess an early TS and endothermic reactions a late one.

In 1953, Leffler $^{2}$ had summarized some similar thoughts in a Science article (title: "Parameters for the Description of Transition States"). Although the Hammond rather than the Leffler publication attracted most of the attention among organic chemists, it is justified to speak today of the Hammond-Leffler postulate (HLP).

Both Hammond and Leffler considered free-energy changes $\Delta \mathrm{G}$ rather than energy changes $\Delta \mathrm{E}$ because their primary goal was to find, on the basis of transition state theory, a relationship between "measured reaction rates and the positions of chemical equilibria" as Hammond formulated it. ${ }^{1}$ Of course such a relationship was known since 1935 when Eyring and others explained the Arrhenius equation in a semi-empirical fashion. ${ }^{3}$ However, Hammond and Leffler wanted to find more precise information about the TS in terms of its free energy.

Today we can calculate the free energy and other properties of the TS precisely with quantum chemical means. This has not led to a general verification of the HLP. For the characterization of the TS as being late or early it was implied that the changes in the free energy correlate directly with the changes in the geometry of the reaction complex. Since the latter are dominated by the changes in the energy, $\Delta \mathrm{E}$, of the reaction complex and since it is always possible to explain how enthalpy and free energy changes relate to $\Delta \mathrm{E}$ changes, it is useful for practical reasons to discuss the HLP in terms of $\Delta \mathrm{E}$ changes and the geometry of the TS.

Numerous attempts have been made to rationalize and/or quantify the HLP, of which only a few can be mentioned here. Sola and Toro-Labbét used the hardness of reactants relative to that of the corresponding products as an important indicator for finding out whether the HLP is fulfilled. Manz and Sholl introduced a dimensionless reaction coordinate for quantifying the lateness of TSs. ${ }^{5}$ Gellman and co-workers extended the HLP to catalytic reactions on solid surfaces. ${ }^{6}$ None of these investigations can be considered as verifying and quantifying the HLP, will become in the next section.

\section{Results and Discussion}

The difficult to interpret if reactants approach each other from large distance, being driven e.g. by electrostatic attraction, and, after reacting, separate again to large distance. Also problematic is the application of the HLP in the case of a complicated reaction mechanism involving several bond changes. In all these cases, the quantification of the HLP depends on the definition of a suitable reference point. The relative position of this point to the TS decides on the late or early character of the latter. Such a reference point will be easy to define if $i$ ) a representative reaction path can be determined, which measures the distance from reactants to products by some parameter $s$ and ii) those path areas can be precisely defined in terms of $s$, in which the chemical processes of bond breaking and bond forming take place.

Realizing that the floor line of the reaction valley is a representative path ${ }^{7}$ solves the first task. ${ }^{8}$ Even if a TS does not exist, a representative reaction path can always be determined as we have shown for strongly exothermic reactions without a barrier. ${ }^{9}$ The representative path through the reaction valley is in most cases identical with the IRC (intrinsic reaction coordinate) path of Fukui, which is given in terms of the mass-weighted arc length $s .{ }^{10}$ A reaction can proceed over a large range with only small changes in the reaction complex because interactions are just of the van der Waals type. The chemical processes however are accompanied by large structural changes in the reaction complex and these changes are reflected by a strong curving of the reaction path. ${ }^{8,11}$ The curvature of 
the reaction path is quantified by calculating the scalar curvature $k(\mathrm{~s})$ as the length of the $3 \mathrm{~N}-(\mathrm{L}+1)$-dimensional curvature vector $\mathbf{k}(\mathrm{s})$ in the $3 \mathrm{~N}-(\mathrm{L}+1)$ dimensional reaction valley spanned by the normal coordinates of the vibrational modes of the reaction complex $(\mathrm{N}$ : number of atoms in the reaction complex; L: degrees of translation and rotation, which has to be enhanced by the translation along the reaction path).

In Figure 1, the scalar curvature function $k(\mathrm{~s})$ for the reaction $\cdot \mathrm{OH}\left({ }^{2} \Pi\right)+\mathrm{H}_{2} \rightarrow \mathrm{OH}_{2}+\cdot \cdot \mathrm{H}\left({ }^{2} \mathrm{~S}\right)$ as calculated with quantum chemical methods is shown. The curvature function is analyzed in terms of local mode curvature coupling coefficients ${ }^{12,13}$ so that each curvature peak can be associated with a specific chemical process; for example curvature peak $\mathrm{K} 1$ represents the cleavage of the $\mathrm{HH}$ bond and curvature peak $\mathrm{K} 2$ the formation of a new $\mathrm{OH}$ bond. There are however also negative (resisting) contributions of $\mathrm{OH}$ bond formation to $\mathrm{K} 1$ and $\mathrm{HH}$ bond cleavage to $\mathrm{K} 2$, i.e. both processes take place parallel, only that for $\mathrm{K} 1$ the $\mathrm{HH}$ bond cleavage and for $\mathrm{K} 2$ the $\mathrm{OH}$ bond formation dominates. The curvature minimum at point M1 (between the peaks K1 and K2) is the midpoint of the chemical processes with a linear rather than curved part of the reaction path (i.e. a uniform change of a transient nonclassical 3e-3c structure of the type $\mathrm{HO} \cdots \mathrm{H} \cdots \mathrm{H})$.

We have studied so far 150 chemical reactions both in the gas phase and in solution and have determined reaction valley, reaction path, and the scalar curvature of the reaction path. In each of these cases, the path region, in which the chemical processes take place, could be identified. It turns out that often these path regions are not centered at the TS but shifted into the entrance or exit channel of the reaction depending on the energetics of the reaction. If one determines the center M1 for each of the chemical processes and determines $\Delta \mathrm{s}(\mathrm{TS})$, the distance of M1 from the TS, a parameter is obtained, which quantitatively measures the late/early character of the TS. This is demonstrated for 19 reactions of the type $\mathrm{XH}_{\mathrm{n}}+\mathrm{H}_{2} \rightarrow \mathrm{XH}_{\mathrm{n}+1}+\mathrm{H}$ with $\mathrm{X}=\mathrm{H}, \mathrm{F}, \mathrm{Cl}, \mathrm{Br}, \mathrm{I}, \mathrm{O}, \mathrm{S}$, $\mathrm{Se}, \mathrm{Te}, \mathrm{N}, \mathrm{P}$. As, $\mathrm{Sb}, \mathrm{Bi}, \mathrm{C}, \mathrm{Si}, \mathrm{Ge}, \mathrm{Sn}$, and $\mathrm{Pb}$ in Figure 2 where the reaction energies $\Delta \mathrm{E}_{\mathrm{R}}$ are correlated with the $\Delta \mathrm{s}(\mathrm{TS})$ values. Hence, using the Unified Reaction Valley Approach (URVA) ${ }^{13}$ with sufficiently accurate quantum chemical methods for the calculation of the reaction path, the HLP is verified and set on a quantitative basis.

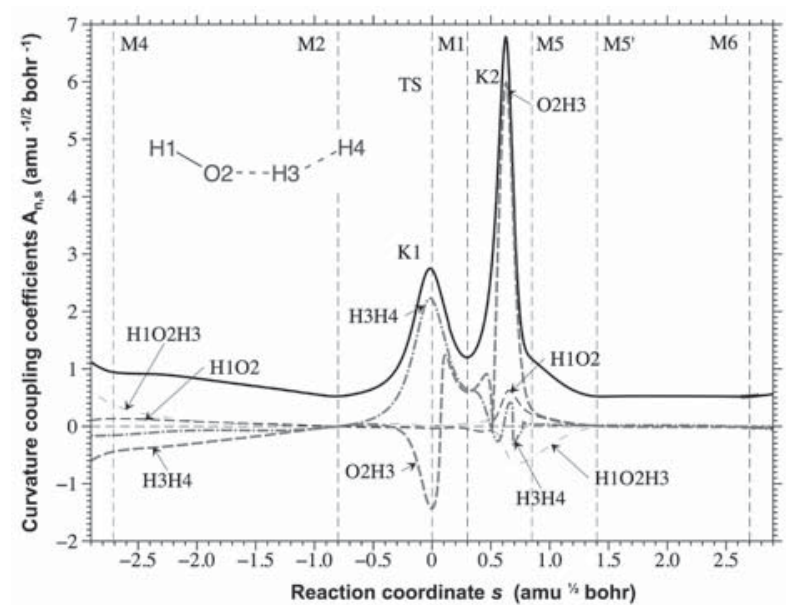

Figure 1. Curvature diagram of the reaction $\mathrm{OH}+\mathrm{H}_{2} \rightarrow \mathrm{OH}_{2}+\mathrm{H}$, representing the change of the scalar curvature $k(\mathrm{~s})$ (bold black line) as a function of the reaction path parameter $s$. The curvature function is analyzed in terms of local mode curvature coupling coefficients $A_{n s}$ (dashed lines), which are associated with the internal coordinates XkY1 (bond lengths) and XkYlZm (bond angles) used to describe the reaction complex. The TS at $s=0$ [amu $1 / 2$ bohr] is given by a dashed vertical line. The positions of the curvature minima (or mechanistically relevant curvature points) Mn are also indicated by dashed vertical lines. The region between two neighboring Mn points is a well-defined reaction phase of the reaction mechanism where typical electronic structure changes of the reaction complex take place. The numbering of the atoms in the reaction complex is given for each reaction. UMP2/6$31 \mathrm{G}(\mathrm{d}, \mathrm{p})$ calculations; for more details see Ref. 14 .

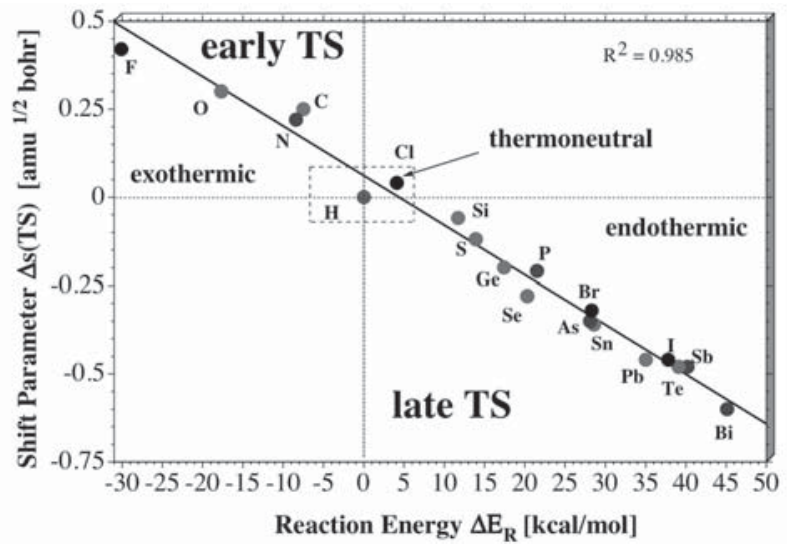

Figure 2. Comparison of the parameter $\Delta \mathrm{s}(\mathrm{TS})$, which determines the shift of the TS relative to the center M1 of the chemical processes of bond breaking or bond formation, with the reaction energy $\Delta \mathrm{E}_{\mathrm{R}}$ for 19 reactions $\mathrm{XH}_{\mathrm{n}}+\mathrm{H}_{2} \rightarrow \mathrm{XH}_{\mathrm{n}+1}+\mathrm{H},(\mathrm{X}=\mathrm{H}, \mathrm{F}, \mathrm{Cl}, \mathrm{Br}, \mathrm{I}, \mathrm{O}, \mathrm{S}, \mathrm{Se}, \mathrm{Te}, \mathrm{N}, \mathrm{P}, \mathrm{As}, \mathrm{Sb}$, $\mathrm{Bi}, \mathrm{C}, \mathrm{Si}, \mathrm{Ge}, \mathrm{Sn}$, and $\mathrm{Pb}$ ). A negative $\Delta \mathrm{s}(\mathrm{TS})$ value indicates a late $\mathrm{TS}$ and a positive $\Delta \mathrm{s}(\mathrm{TS})$ value an early TS. The central atom $\mathrm{X}$ is given for each $\mathrm{XH}_{\mathrm{n}}+\mathrm{H}_{2} \rightarrow \mathrm{XH}_{\mathrm{n}+1}+\mathrm{H}$ reaction. $\mathrm{CCSD}(\mathrm{T}) / \mathrm{cc}-\mathrm{pV} 5 \mathrm{Z}$ calculations; for more details see Ref. 14. 
We conclude that for bond-breaking/forming reactions the HLP is valid and quantified by determining the reaction path curvature.

\section{Acknowledgements}

This work was financially supported by the National Science Foundation, Grant CHE 1152357. We thank SMU for providing computational resources.

\section{References}

1. Hammond, G.S. A Correlation of Reaction Rates. J. Am. Chem. Soc. 1955, 77, 334

2. Leffler, J.E., Parameters for the Description of Transition States. Science, 1953, 117, 340 .

3. Eyring, H. The Activated Complex in Chemical Reactions. $J$. Chem. Phys. 1935, 3, 107.

4. Sola,M.; Toro-Labbé, A. The Hammond postulate and the principle of maximum hardness in some intramolecular rearrangement reactions. J. Phys. Chem. A, 1999, 103, 8847.

5. Manz, T.A.; Sholl, D.S. A dimensionless reaction coordinate for quantifying the lateness of transition states. J. Comp. Chem., 2010, 31,1528

6. Gellman, A.J. The Influence of Catalytic Surfaces on the Barriers to Elementary Surface Reaction Steps. J. Phys. Chem. B., 2002, $106,10510$.

7. Kraka,E.; Joo, H.; Cremer, D. A stunning example for a spontaneous reaction with a complex mechanism: the vinylideneacetylene cycloaddition reaction. Mol. Phys., 2010, 19-20, 2667.

8. Cremer, D.; Kraka, E. From Molecular Vibrations to Bonding, Chemical Reactions, and Reaction Mechanism. Curr. Org. Chem., 2010, 14, 1524 .
9. Joo, H.; Kraka, E.; Quapp, W.; Cremer, D. The Mechanism of a Barrierless Reaction: Hidden Transition State and Hidden Intermediate in the Reaction of Methylene with Ethene. Mol. Phys. 2007, 105, 2697.

10. Fukui, K. The Path of Chemical Reactions - The IRC Approach Acc. Chem. Res. 1981, 14, 363.

11. Kraka, E.; Cremer, D. Computational Analysis of the Mechanism of Chemical Reactions in Terms of Reaction Phases: Hidden Intermediates and Hidden Transition State. Acc. Chem. Res., 2010, 43,591 .

12. Konkoli, Z.; Cremer, D.; Kraka, E. Unified Reaction Valley Approach: Mechanism of the Reaction $\mathrm{CH}_{3}+\mathrm{H}_{2} \rightarrow \mathrm{CH}_{4}+\mathrm{H}$. $J$. Phys. Chem. A, 1997, 101, 1742.

13. Kraka, E. Reaction Path Hamiltonian and the Unified Reaction Valley Approach, in Wiley Interdisciplinary Reviews: Computational Molecular Science, Vol.1, Allen, W.; Schreiner, P.R., Edts., Wiley, New York, 2011, p. 531.

14. Kraka, E.; Zou, W.; Freindorf, M.; Cremer, D. Energetics and Mechanism of the Hydrogenation of, $\mathrm{XH}_{\mathrm{n}}$ for Group IV to Group VII Elements X, J. Chem. Theor. Comp. in press.

\section{Dieter Cremer $^{*}$ \& Elfi Kraka}

CATCO Group, Department of Chemistry, Southern Methodist University, 3215 Daniel Ave, Dallas, Texas, 75275-03114, USA.

*e-mail: dcremer@smu.edu 